\title{
BUPROPION, SMOKING CESSATION, AND HEALTH-RELATED QUALITY OF LIFE FOLLOWING AN ACUTE MYOCARDIAL INFARCTION
}

\author{
David Dong Qi Zhang ${ }^{1}$, Mark J Eisenberg ${ }^{1,2,3,4}$, Sonia M Grandi ${ }^{2}$, Lawrence Joseph ${ }^{4,5}$, Jennifer O'Loughlin ${ }^{6}$, \\ Gilles Paradis $^{4,7}$, Pedro Lozano ${ }^{8}$, Kristian B Filion ${ }^{1,2,4}$ \\ ${ }^{1}$ Faculty of Medicine, McGill University, Montreal, QC, Canada, ${ }^{2}$ Division of Clinical Epidemiology, Jewish \\ General Hospital/McGill University, Montreal, QC, Canada, ${ }^{3}$ Division of Cardiology, Jewish General \\ Hospital/McGill University, Montreal, QC, Canada, ${ }^{4}$ Department of Epidemiology, Biostatistics and \\ Occupational Health, McGill University, Montreal, QC, Canada, ${ }^{5}$ Division of Clinical Epidemiology, McGill \\ University Health Centre, Montreal, QC, Canada, ${ }^{6} \mathrm{CRCHUM}$ and the Department of Social and \\ Preventive Medicine, Université de Montréal, Montreal, QC, Canada, ${ }^{7}$ Research Institute, McGill \\ University Health Centre, Montreal, QC, Canada, ${ }^{8}$ DVA Medical Center, Oklahoma City, OK, USA
}

\section{Corresponding Author: kristian.filion@mcgill.ca}

\begin{abstract}
Background

The use of bupropion, a smoking cessation aid, has been associated with improved health-related quality of life (HRQOL) in the general population of smokers; but, its effect on HRQOL in post-myocardial infarction (MI) patients remains unknown.
\end{abstract}

\section{Objectives}

To examine the effect of bupropion on HRQOL in post-MI patients who are attempting to quit smoking.

\section{Methods}

To accomplish this objective, we used data from a randomized, double-blind, placebo-controlled trial in 392 hospitalized post-MI patients. Treatment duration was 9 weeks, and follow-up was 12 months. HRQOL was assessed via the EuroQol-5D (EQ-5D) questionnaire, which includes 5 dimensions (mobility, self-care, daily activities, pain/discomfort, and anxiety/depression). Analyses were restricted to patients $(n=225)$ who completed the EQ-5D at baseline, 6 months, and 12 months.

\section{Results}

Patients randomized to bupropion $(n=109)$ and those randomized to placebo $(n=116)$ experienced similar improvements in HRQOL during follow-up (difference in change in EQ-5D index from baseline to 6 months $=0.02,95 \%$ confidence interval $[\mathrm{CI}]=-0.04,0.08$; from baseline to 12 months $=0.02,95 \% \mathrm{CI}=$ $-0.04,0.08)$. No between-group differences were observed in any of the 5 dimensions. Similar improvements in HRQOL were observed between patients who remained abstinent and those who relapsed. Lower baseline HRQOL, defined as having a HRQOL that was less than the median value, was associated with decreased smoking abstinence at 12 months follow-up (odds ratio $[\mathrm{OR}]=0.39,95 \% \mathrm{CI}=$ $0.22,0.68)$.

\section{Conclusions}

Bupropion does not improve HRQOL among patients attempting to quit smoking post-MI.

Key Words: Smoking cessation, myocardial infarction, bupropion, health-related quality of life 
$\mathrm{B}$ upropion, an antidepressant with noradrenergic and dopaminergic activities, is also used as a smoking cessation agent. It has been shown to be effective when prescribed as a smoking cessation therapy in the general population, with an absolute increase in the prevalence of abstinence at 12 months of up to $14.7 \%$ compared to placebo. ${ }^{1}$ It facilitates smoking cessation by relieving withdrawal symptoms. ${ }^{2}$ Several studies have demonstrated that bupropion also improves health-related quality of life (HRQOL), a reflection of one's physical, psychological, and social functioning in relation to health ${ }^{3}$, when used in patients with depression $^{4-6}$, cancer ${ }^{7 ; 8}$, or in those trying to quit smoking. ${ }^{9}$ This association is likely related to its mood-enhancing properties, as well as to the relief of nicotine withdrawal symptoms. However, the effect of bupropion on HRQOL in patients attempting to quit smoking immediately after a myocardial infarction (MI) is unknown. Our primary objective was therefore to examine the effect of bupropion on HRQOL among smokers attempting to quit immediately after a MI. Our secondary objectives were to determine the effect of smoking status on change in HRQOL during the 12 months post-MI and to assess the effect of HRQOL at baseline on the prevalence of subsequent abstinence.

\section{METHODS}

\section{Study Design}

To achieve these objectives, we used data from the ZESCA trial (ClinicalTrials.gov Identifier NCT00689611), a multi-center, randomized, double-blind, placebo-controlled trial of bupropion as a pharmacological aid for smoking cessation in patients hospitalized with a MI. A detailed description of the ZESCA trial has been reported elsewhere. ${ }^{10}$ A total of 392 patients were randomized to either 9 weeks of bupropion (150 $\mathrm{mg}$ once daily for 3 days, then $150 \mathrm{mg}$ twice daily) or placebo. Prior to initiation of study medication, all patients received a standardized nonpharmacologic smoking cessation intervention.

Telephone follow-ups were conducted at 1 and 2 weeks, and clinic visits were held at 4 and 9 weeks as well as at 6 and 12 months. Smoking abstinence was biochemically validated by an exhaled carbon monoxide level of $\leq 10 \mathrm{ppm}$ during all clinic visits. Patients lost to follow-up were assumed to have returned to smoking. The primary endpoint of the ZESCA trial was point prevalence smoking abstinence at 12 months. Secondary endpoints included side effects and safety, which were assessed during telephone follow-ups and clinic visits.

\section{Study Population}

Patients who were $\geq 18$ years old, who were active smokers (having smoked on average $\geq 10$ cigarettes per day in the past year), and who suffered a MI with $\geq 24$ hours hospitalization were recruited in the trial. MI was defined as having a positive troponin $\mathrm{T}$, Troponin $\mathrm{I}$, or CKMB levels as well as $\geq 1$ of the following: 1) ischemic symptoms (i.e., typical chest pain) for at least 20 minutes; 2) ECG changes indicative of ischemia (ST-segment elevation or depression); or 3) development of pathological $Q$ waves on the ECG. Patients undergoing percutaneous coronary intervention (PCI) and/or coronary artery bypass graft surgery $(\mathrm{CABG})$ were eligible for enrollment. In addition, patients had to be motivated to quit smoking. Exclusion criteria consisted of a history of or predisposition to seizures, a history of anorexia nervosa or bulimia, a history of suicidal events, liver or renal impairment, pregnancy, lactation, excessive consumption of alcohol, and current use of any medical smoking cessation aids or any medications that lower seizure threshold. Research ethics approval was obtained at all participating sites, and all patients provided written informed consent.

\section{HRQOL}

HRQOL was measured using the EuroQol-5D (EQ-5D) questionnaire at baseline, 6 months, and 12 months. The EQ-5D consists of five items, each measuring a specific dimension of HRQOL: mobility, self-care, daily activities, pain/discomfort, and anxiety/depression. ${ }^{11}$ Patients were asked to rate their current state of health as "no problems", "some problems", or "severe problems" for each of the 5 dimensions, and these data were converted into a 1-digit level number. Thus, "no problems" was categorized as

J Popul Ther Clin Pharmacol Vol 21(3):e346-e356; October 8, 2014 
level 1, "some problems" as level 2, and "severe problems" as level 3. Combining the digits for each dimension yielded a 5-digit number that was then converted using a country-specific value set (preferential weights) to a single summary index score. ${ }^{12} \mathrm{We}$ employed the United States version of the value sets in the present study. ${ }^{12}$ In addition, patients rated their current state of health using the EQ-5D Visual Analogue Scale (VAS), a $20 \mathrm{~cm}$ scale ranging from 0 to 100 , with 100 representing the best imaginable health state and 0 representing the worst imaginable health state. The EQ-5D questionnaire has been shown to be a valid, reliable, and responsive instrument to measure HRQOL in patients with an acute coronary syndrome. ${ }^{13-15}$ Inclusion in the present study was restricted to participants who completed the EQ5D questionnaire at baseline, 6 months, and 12 months.

\section{Other Measures}

Sociodemographic characteristics and medical history were obtained at baseline evaluation, at which time patients were also assessed for depression using the Beck Depression Inventory II $(\mathrm{BDI}-\mathrm{II})^{16}$ and nicotine dependence using the Fagerström Test for Nicotine Dependence (FTND). ${ }^{17}$

\section{Statistical Analyses}

In our primary analyses, we examined the effect of bupropion on HRQOL; a modified intention-totreat approach was used, with patients who completed the EQ-5D questionnaire analyzed according to the treatment group (bupropion or placebo) to which they were randomized. We calculated between-group differences in EQ-5D index and VAS scores with $95 \%$ confidence intervals (CI). Change in EQ-5D score was obtained from the difference in scores between baseline and follow-up, and between-group comparison was performed to yield the difference in change and the 95\% CI. In addition, we examined change in HRQOL in dimensionspecific analyses. To facilitate the interpretation of dimension-specific results, we dichotomized each dimension into "no problems" (levels 1 and 2) and "problems" (level 3), and between-group comparisons were performed for each dimension.
Furthermore, to assess the impact of country where the participant was recruited, we stratified analyses examining the change in EQ5D score by developed/developing country status.

In secondary analyses, we categorized patients as "persistent quitters", defined as abstinence at all follow-ups, and "smokers", defined as reported smoking on at least 1 occasion. We then examined change in HRQOL by smoking status by generating between-group differences and $95 \%$ CI. In addition, to investigate the effect of baseline HRQOL on the prevalence of smoking abstinence at 6 and 12 months follow-ups, we dichotomized baseline HRQOL at the median EQ5D index score of the study population, and we used multiple logistic regression to adjust for potential confounders. Candidate variables for potential inclusion in this analysis were age, sex, treatment group, number of years smoked, number of previous attempts to quit, BDI score, FTND score, previous use of antidepressants, presence of other smokers at home, prior diabetes mellitus, prior MI, prior hyperlipidemia, prior hypertension, prior cerebrovascular accident/transient ischemic attack, treatment of MI with thrombolytic therapy, and developed/developing country. Finally, these candidate baseline variables were also examined as predictors of improved HRQOL at 12 months post-cessation. All statistical analyses were performed in SAS version 9.2 (Cary, NC).

\section{RESULTS}

\section{Patient Characteristics}

A total of 225 patients from the ZESCA trial were included in our analysis (109 in the bupropion group and 116 in the placebo group). The mean age was 54 (standard deviation $[\mathrm{SD}]=10$ ) years, and $84.4 \%$ were male. Patients had smoked a mean of 33 years $(\mathrm{SD}=11.7)$. Compared to patients randomized to placebo, a greater proportion of patients randomized to bupropion had received thrombolytic therapy for their MI (bupropion $=50.5 \%$, placebo $=37.1 \%$, betweengroup difference $=13.4 \%, 95 \% \mathrm{CI}=0.5,26.2$ ) . The two treatment groups were well balanced for all other characteristics (Table 1).

J Popul Ther Clin Pharmacol Vol 21(3):e346-e356; October 8, 2014 
TABLE 1 Baseline demographic and clinical characteristics of post-acute myocardial infarction patients attempting to quit smoking.

\begin{tabular}{|l|c|c|c|}
\hline & Bupropion (n=109) & Placebo (n=116) & Difference (95\% CI) \\
\hline Age (SD) & $53.7(9.6)$ & $53.6(10.7)$ & $0.08(-2.61,2.77)$ \\
\hline Male (\%) & 86.2 & 82.8 & $3.5(-6.0,12.9)$ \\
\hline Number of years smoked (range) & $32.3(3.0-67.0)$ & $33.5(4.00-63.0)$ & $-1.26(-4.34,1.82)$ \\
\hline Presence of other smokers at home (\%) & 28.4 & 35.3 & $-6.9(-19.0,5.2)$ \\
\hline \# of previous attempts to quit (SD) & $1.8(4.9)$ & $2.3(3.0)$ & $-0.42(-1.50,0.65)$ \\
\hline BDI score > 14 (\%) & 11.9 & 16.4 & $-4.5(-13.5,4.6)$ \\
\hline FTND score (SD) & $5.4(2.2)$ & $5.5(2.0)$ & $-0.12(-0.68,0.43)$ \\
\hline Previous antidepressant use (\%) & 9.2 & 8.6 & $0.6(-6.9,8.0)$ \\
\hline Prior hyperlipidemia (\%) & 49.5 & 48.3 & $1.3(-11.8,14.3)$ \\
\hline Prior hypertension (\%) & 33.0 & 37.9 & $-4.9(-17.4,7.6)$ \\
\hline Prior diabetes mellitus (\%) & 20.2 & 12.1 & $8.1(-1.5,17.7)$ \\
\hline Prior MI (\%) & 16.5 & 22.4 & $-5.9(-16.2,4.4)$ \\
\hline Prior CVA/TIA (\%) & 0.9 & 0.9 & $0.1(-2.4,2.5)$ \\
\hline STEMI (\%) & 68.8 & 69.0 & $-0.2(-12.3,11.9)$ \\
\hline Thrombolytic therapy (\%) & 50.5 & 37.1 & $13.4(0.5,26.2)$ \\
\hline $\begin{array}{l}\text { Angiography/Cardiac catheterization } \\
(\%)\end{array}$ & 59.6 & 68.1 & $-8.5(-21.0,4.1)$ \\
\hline PTCA/PCI (\%) & 46.8 & 52.6 & $-5.8(-18.8,7.3)$ \\
\hline CABG (\%) & 5.5 & 7.8 & $-2.3(-8.7,4.2)$ \\
\hline CHF (\%) & 4.6 & 4.3 & $0.3(-5.1,5.7)$ \\
\hline Developing country (\%) & 42.2 & 36.2 & $6.0(-6.8,18.7)$ \\
\hline
\end{tabular}

Abbreviations: $\mathrm{CI}=$ Confidence Interval; $\mathrm{SD}=$ Standard Deviation; $\mathrm{BDI}=$ Beck Depression Inventory; FTND $=$ Fagerström Test for Nicotine Dependence; MI = Myocardial Infarction; CVA = Cerebrovascular Accident; TIA = Transient Ischemic Attack; STEMI = ST-Segment Elevation Myocardial Infarction; PTCA = Percutaneous Cardiac Angiography; PCI = Percutaneous Coronary Intervention; $\mathrm{CABG}=$ Coronary Artery Bypass Graft; $\mathrm{CHF}=$ Congestive Heart Failure.

\section{Bupropion and Smoking Prevalence}

No difference in point prevalence smoking was observed between the 2 groups at 6 months (bupropion $=57.8 \%$, placebo $=51.7 \%$, betweengroup difference $=6.1 \%, 95 \% \mathrm{CI}=-6.9,19.1)$ and 12 months follow-ups (bupropion $=59.6 \%$, placebo $=49.1 \%$, between-group difference $=$ $10.5 \%, 95 \% \mathrm{CI}=-2.5,23.4)$.

\section{Bupropion and HRQOL}

HRQOL improved at 6- and 12-month follow-ups (Figure 1), with similar improvements observed in the 2 treatment groups (difference in change in EQ-5D index from baseline to 6 months $=0.02$,
95\% CI $=-0.04,0.08$; from baseline to 12 months $=0.02,95 \% \mathrm{CI}=-0.04,0.08)$. Similar results were obtained when HRQOL was assessed using the EQ-5D VAS (Figure 2). In sensitivity analyses, we stratified the change in EQ-5D index and VAS scores by developed/developing country status; these analyses produced results that were similar to those of our primary analysis (data not shown).

Analysis of each of the EQ-5D dimensions revealed that patients in both treatment groups reported fewer problems with regards to motility, self-care, and usual activities at 6 and 12 months post-MI compared to baseline, but experienced similar levels of pain/discomfort and anxiety/depression (Table 2). Similar trends were observed in each of the 2 treatment groups. 
FIG. 1 Change in health-related quality of life among patients attempting to quit smoking postmyocardial infarction randomized to bupropion versus that in patients randomized to placebo with change measured using the EuroQol-5D (EQ-5D) index score.

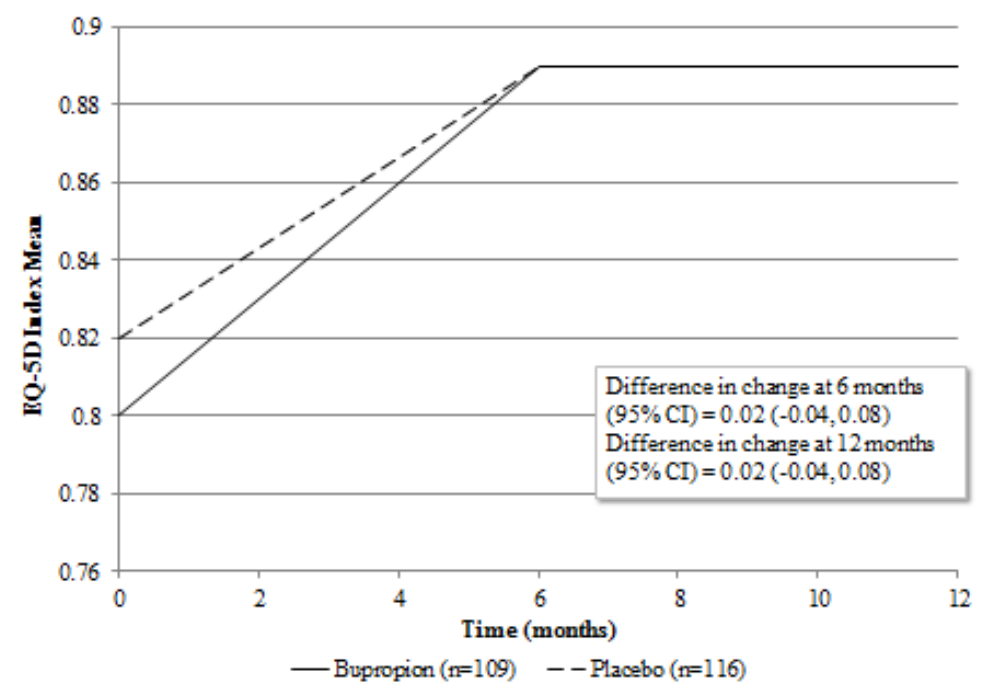

Abbreviations: $\mathrm{CI}=$ Confidence Interval

FIG. 2 Change in health-related quality of life among patients attempting to quit smoking postmyocardial infarction randomized to bupropion versus that in patients randomized to placebo with change measured using the EuroQol-5D (EQ-5D) visual analogue score (VAS).

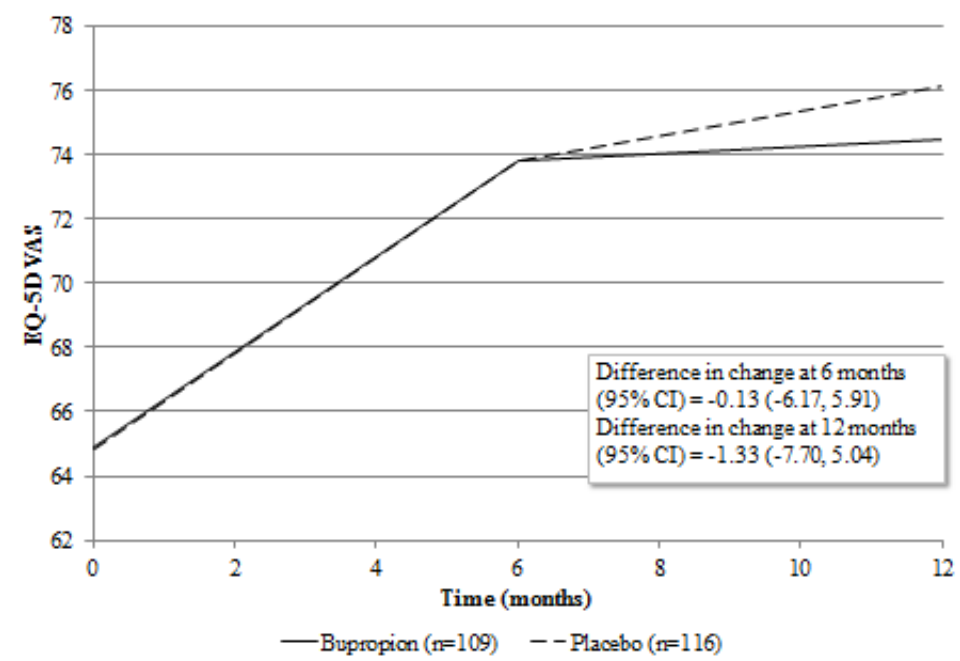

Abbreviations: $\mathrm{CI}=$ Confidence Interval

J Popul Ther Clin Pharmacol Vol 21(3):e346-e356; October 8, 2014 (C) 2014 Canadian Society of Pharmacology and Therapeutics. All rights reserved e350 
TABLE 2 EQ-5D dimensional health-related quality of life comparison of post-acute myocardial infarction smokers treated with bupropion versus placebo.

\begin{tabular}{|c|c|c|c|}
\hline & Bupropion $(n=109)$ & Placebo $(n=116)$ & Difference (95\% CI) \\
\hline \multicolumn{4}{|l|}{ Mobility - \% reported problems } \\
\hline Baseline & 36.7 & 32.8 & $3.9(8.5,16.4)$ \\
\hline 6 months & 17.4 & 19.8 & $-2.4(-12.6,7.8)$ \\
\hline 12 months & 19.3 & 12.9 & $6.3(-3.3,15.9)$ \\
\hline Change at 6 months $(95 \% \mathrm{CI})$ & $-19(-30,-9)$ & $-13(-23,-3)$ & $-6(-21,8)$ \\
\hline Change at 12 months $(95 \% \mathrm{CI})$ & $-17(-28,-7)$ & $-20(-29,-10)$ & $2(-12,17)$ \\
\hline \multicolumn{4}{|l|}{ Self-Care $-\%$ reported problems } \\
\hline Baseline & 12.8 & 10.3 & $2.5(-5.9,10.9)$ \\
\hline 6 months & 3.7 & 3.4 & $0.2(-4.6,5.1)$ \\
\hline 12 months & 2.8 & 4.3 & $-1.6(-6.4,3.2)$ \\
\hline Change at 6 months $(95 \% \mathrm{CI})$ & $-9(-16,-2)$ & $-7(-14,0)$ & $-2(-12,7)$ \\
\hline Change at 12 months $(95 \% \mathrm{CI})$ & $-10(-17,-3)$ & $-6(-13,1)$ & $-4(-13,5)$ \\
\hline \multicolumn{4}{|c|}{ Usual Activities - \% reported problems } \\
\hline Baseline & 27.5 & 32.8 & $-5.2(-17.2,6.7)$ \\
\hline 6 months & 16.5 & 16.4 & $0.1(-9.6,9.8)$ \\
\hline 12 months & 14.7 & 14.7 & $0.0(-9.2,9.3)$ \\
\hline Change at 6 months $(95 \% \mathrm{CI})$ & $-11(-21,-1)$ & $-16(-27,-6)$ & $5(-9,19)$ \\
\hline Change at 12 months $(95 \% \mathrm{CI})$ & $-13(-24,-2)$ & $-18(-29,-8)$ & $5(-10,20)$ \\
\hline \multicolumn{4}{|c|}{ Pain/Discomfort - \% reported problems } \\
\hline Baseline & 33.9 & 29.3 & $4.6(-7.5,16.8)$ \\
\hline 6 months & 32.1 & 23.3 & $8.8(-2.8,20.5)$ \\
\hline 12 months & 31.2 & 31.9 & $-0.7(-12.9,11.4)$ \\
\hline Change at 6 months $(95 \% \mathrm{CI})$ & $-2(-12,8)$ & $-6(-17,5)$ & $4(-10,19)$ \\
\hline Change at 12 months $(95 \% \mathrm{CI})$ & $-3(-15,9)$ & $3(-8,13)$ & $-5(-21,11)$ \\
\hline \multicolumn{4}{|c|}{ Anxiety/Depression -\% reported problems } \\
\hline Baseline & 24.8 & 27.6 & $-2.8(-14.3,8.7)$ \\
\hline 6 months & 29.4 & 25.9 & $3.5(-8.2,15.2)$ \\
\hline 12 months & 23.9 & 23.3 & $0.6(-10.5,11.7)$ \\
\hline Change at 6 months $(95 \% \mathrm{CI})$ & $5(-6,16)$ & $-2(-12,9)$ & $6(-9,22)$ \\
\hline Change at 12 months $(95 \% \mathrm{CI})$ & $-1(-12,10)$ & $-4(-15,7)$ & $3(-12,19)$ \\
\hline
\end{tabular}

Abbreviations: $\mathrm{CI}=$ Confidence Interval

\section{HRQOL by Smoking Status}

All patients reported better EQ-5D index scores at 6- and 12-month follow-ups; but, no difference in change in index score was observed between smokers and persistent quitters (Figure 2). Differences were observed between the index scores of smokers and persistent quitters at 12month follow-up (between-group difference = $0.05,95 \% \mathrm{CI}=-0.09,-0.02)$. When HRQOL was assessed using the VAS rather than index score, we found that persistent quitters improved more than smokers during 6 months post-cessation (between-group difference $=-7.18,95 \% \mathrm{CI}=-$ 13.00, -1.36)(Figure 4). However, this difference did not persist at 12 months (between-group difference $=-4.97,95 \% \mathrm{CI}=-11.26,1.31)$. Similar trends were observed when analyses were conducted by treatment group (data not shown). 
FIG. 3 Change in health-related quality of life among patients who remained abstinent in the 12 months post-myocardial infarction versus that in patients who returned to smoking with change measured using the EuroQol-5D (EQ-5D) index score.

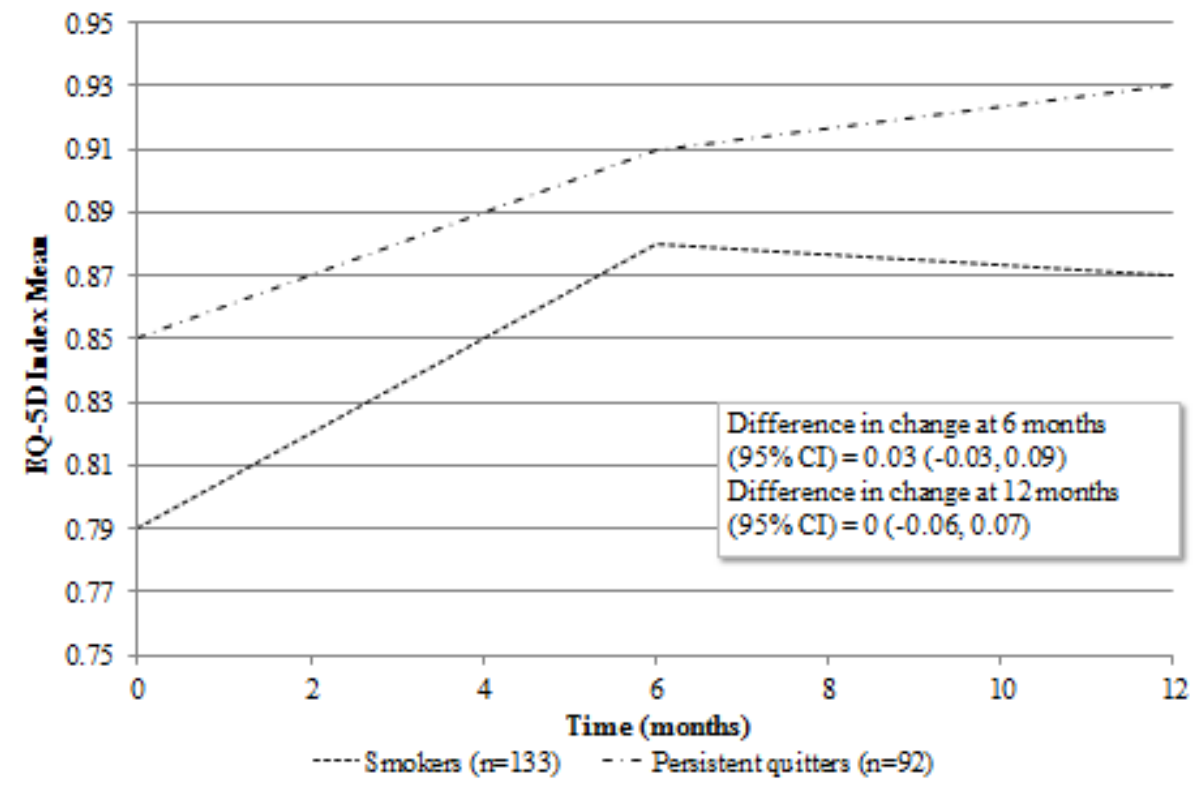

Abbreviations: $\mathrm{CI}=$ Confidence Interval

FIG. 4 Change in health-related quality of life among patients who remained abstinent in the 12 months post-myocardial infarction versus that in patients who returned to smoking with change measured using the EuroQol-5D (EQ-5D) visual analogue score (VAS).

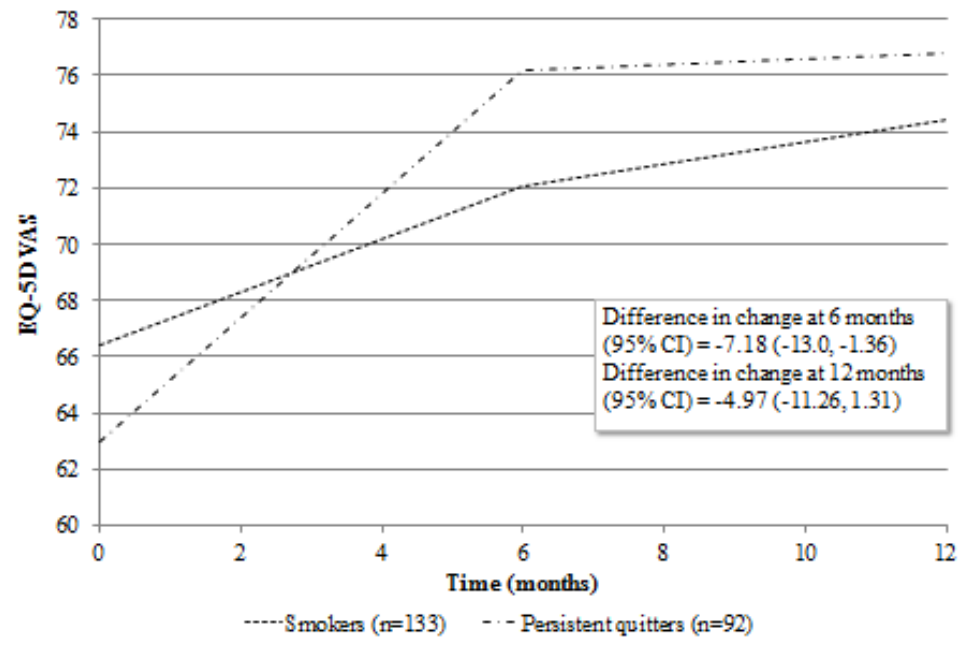

Abbreviations: $\mathrm{CI}=$ Confidence Interval 
Predictors of Abstinence and HRQOL at 12 Months

After adjusting for treatment group, we found that lower HRQOL at baseline was associated with lower abstinence at 12 months (odds ratio [OR] = $0.39,95 \% \mathrm{CI}=0.22,0.68)$. Adjustment for additional potential confounders did not materially alter this association (data not shown). Age, BDI > 14, having received thrombolytic therapy, and lower HRQOL at baseline were the most important predictors of change in HRQOL at 12 months (Table 3).

TABLE 3 Baseline predictors of improved health-related quality of life at 12 months post-MI

\begin{tabular}{|l|l|}
\hline Variable* & Change in EQ-5D Index Score (95\% CI) \\
\hline Age & $-0.004(-0.007,-0.001)$ \\
\hline BDI score > 14 & $0.13(0.04,0.23)$ \\
\hline Thrombolytic therapy & $0.12(0.05,0.19)$ \\
\hline Lower baseline HRQOL & \\
\hline
\end{tabular}

Abbreviations: CI = Confidence Interval; BDI = Beck's Depression Inventory; HRQOL = Health-Related Quality of Life *Other variables considered but not included in the final model were sex, treatment group, number of years smoked, number of previous attempts to quit, Fagerström Test for Nicotine Dependence score, previous use of antidepressants, presence of other smokers at home, prior diabetes mellitus, prior MI, prior hyperlipidemia, prior hypertension, and prior cerebrovascular accident/transient ischemic attack. †Lower baseline HRQOL was defined as lower than the median EQ-5D index score of the study population.

\section{DISCUSSION}

Our study was designed to examine the effect of bupropion on HRQOL among smokers attempting to quit immediately after a MI. We found that the use of bupropion as a smoking cessation aid was not associated with improved HRQOL over the period of 1 year post-MI compared with placebo. This null finding may be explained by the observed no between-group differences in smoking at 6 and 12 months, which is consistent with results from the primary analysis of the ZESCA trial. ${ }^{10}$ Regardless of treatment group, patients experienced improved HRQOL following their MI, especially concerning their ability to move, to care for themselves, and to perform usual activities. Although differences in index scores at 12 months follow-up and in VAS score at 6 months follow-up between smokers and persistent quitters were observed, patients who remained abstinent throughout the year had similar improvements in HRQOL as those who relapsed during the year. Lower HRQOL at baseline was a predictor of lower abstinence at 12 months, and young age, BDI score > 14, having received thrombolytic therapy and reporting a lower HRQOL at baseline were predictors of improved HRQOL at 12 months.

To our knowledge, this is the first study to examine the effect of bupropion on HRQOL in the setting of smoking cessation after a MI. Results from previous studies have shown that the use of bupropion as an antidepressant is associated with significant improvements in HRQOL compared to placebo. ${ }^{4-8}$ Furthermore, a recent large RCT of pharmacotherapy-mediated smoking cessation in healthy smokers demonstrated that the use of bupropion as a smoking cessation aid is associated with improved quality of life at 12-, 24-, and 52week follow-ups compared to placebo. ${ }^{9}$ These findings were not replicated in our study, suggesting that any potential benefits of bupropion on HRQOL are masked by the overall improved HRQOL that occurs in the year post-MI.

J Popul Ther Clin Pharmacol Vol 21(3):e346-e356; October 8, 2014 
Interestingly, although it is well known that depression is a common morbidity following an $\mathrm{MI}^{18}$, the lack of improvement in HRQOL with bupropion compared to placebo suggests that its antidepressant action may be minimal following an acute coronary event, despite a dosing similar to that used to treat depression. The heavy health burden of an MI and its natural recovery course likely overshadow the mood-enhancing properties of bupropion. Furthermore, our patients were comparatively older, consisted of a greater proportion of males, and were smokers of longer duration, all of which could contribute to the observed differences between this previous study and the present one.

Our finding that both patients who remained abstinent and those who relapsed experienced similar improvements in HRQOL adds to a body of conflicting literature on the effect of smoking cessation on HRQOL. Several observational studies have suggested that smoking cessation leads to improved HRQOL in otherwise healthy smokers. ${ }^{19-24}$ However, the picture is less defined for patients with cardiovascular diseases. Some studies have found no improvement in HRQOL with smoking cessation ${ }^{25 ; 26}$, whereas an observational study involving 1,432 patients who underwent PCI found that patients who quit smoking had significantly greater improvements in HRQOL compared to those who continued smoking. ${ }^{27}$ Furthermore, smoking has been found to be an important negative predictor of HRQOL after CABG. ${ }^{28}$ Our results support the former findings; however, it is possible that improved HRQOL due to recovery from MI masks the improvement due to smoking cessation.

Patients who report a lower HRQOL at baseline are more likely those who have the most medical comorbidities and, due to poor health status, experience more difficulties remaining abstinent during the 12-month follow-up. Our finding that lower baseline HRQOL is associated with lower abstinence is in contradiction with results from a previous study. ${ }^{26}$ However, differences in the measurement of HRQOL and the definition of impairment likely account for the discrepancy.

Our study has some limitations. First, our study was limited to HRQOL 1 year post-MI, and the long-term effect of bupropion on HRQOL remains unknown. Second, inclusion was restricted to participants in the ZESCA trial who completed EQ-5D questionnaires at baseline, 6 months, and 12 months. The HRQOL of those who did not complete all 3 EQ-5D questionnaires remains unknown, and the possibility of selection bias cannot be excluded, as we are unable to compare data between those who completed the questionnaires and those who did not. Third, in contrast to most other HRQOL studies, we employed the EQ-5D questionnaire, a preferencebased valuation of health state, instead of more commonly used questionnaires such as the SF-36 questionnaire. However, the EQ-5D questionnaire has been shown to have good validity and reliability, and is highly accepted by patients with acute coronary syndrome. ${ }^{13-15}$ Finally, as we did not measure HRQOL during the 9 weeks of active treatment with bupropion, we cannot rule out a transient effect of the drug on HRQOL.

\section{CONCLUSION}

We found that bupropion does not improve HRQOL compared to placebo. However, improvements in HRQOL were observed in both treatment groups post-MI. While data suggest similar HRQOL among persistent smokers and abstainers, smoking cessation is nonetheless crucial in the long-term prognosis of patients who have suffered a MI, given its other associated health benefits.

\section{Acknowledgments}

The authors thank the study site personnel who contributed to the study and Patrick Bélisle (McGill University Health Centre) for help analyzing the data.

Mrs. Grandi holds a Canadian Institutes of Health Research (CIHR) Doctoral Award - Frederick Banting and Charles Best Canada Graduate Scholarship. Dr. O'Loughlin holds the Canada Research Chair in the Early Determinants of Adult Chronic Disease. Dr. Paradis holds a CIHR Chair in Applied Public Health Research. Dr. Filion holds a CIHR New Investigator Award.

J Popul Ther Clin Pharmacol Vol 21(3):e346-e356; October 8, 2014 


\section{Funding}

This ZESCA trial was funded by the Canadian Institutes of Health Research (Grant NCT64989) and the Heart and Stroke Foundation of Quebec. The funding organizations were not involved in the design and conduct of the study; in the collection, management, analysis, and interpretation of the results; or in the preparation, review, or approval of the manuscript. Clinicaltrials.gov Identifier: NCT00689611

\section{Competing Interests}

Dr. Eisenberg received funding from Pfizer Canada Inc., to conduct the Evaluation of Varenicline (Champix) in Smoking Cessation for Patients Post-Acute Coronary Syndrome (EVITA) Trial (NCT00794573). All other authors have no potential conflicts to disclose.

\section{REFERENCES}

1. Jorenby DE, Leischow SJ, Nides MA, et al. A controlled trial of sustained-release bupropion, a nicotine patch, or both for smoking cessation. $\mathrm{N}$ Engl J Med 1999 March 4;340(9):685-91.

2. Hughes JR, Goldstein MG, Hurt RD, Shiffman S. Recent advances in the pharmacotherapy of smoking. JAMA 1999 January 6;281(1):72-6.

3. Guyatt GH, Feeny DH, Patrick DL. Measuring health-related quality of life. Ann Intern Med 1993 April 15;118(8):622-9.

4. Dunner DL, Kwong WJ, Houser TL, et al. Improved health-related quality of life and reduced productivity loss after treatment with bupropion sustained release: A study in patients with major depression. Prim Care Companion J Clin Psychiatry 2001 February;3(1):10-6.

5. Fortner MR, Brown K, Varia IM, et al. Effect of Bupropion SR on the quality of life of elderly depressed patients with comorbid medical disorders. Prim Care Companion J Clin Psychiatry 1999 December;1(6):174-9.

6. Hewett K, Chrzanowski W, Jokinen R, et al. Double-blind, placebo-controlled evaluation of extended-release bupropion in elderly patients with major depressive disorder. J Psychopharmacol 2010 April;24(4):521-9.

7. Cullum JL, Wojciechowski AE, Pelletier G, Simpson JS. Bupropion sustained release treatment reduces fatigue in cancer patients. Can J Psychiatry 2004 February;49(2):139-44.
8. Moss EL, Simpson JS, Pelletier G, Forsyth P. An open-label study of the effects of bupropion SR on fatigue, depression and quality of life of mixed-site cancer patients and their partners. Psychooncology 2006 March;15(3):259-67.

9. Hays JT, Croghan IT, Baker CL, Cappelleri JC, Bushmakin AG. Changes in health-related quality of life with smoking cessation treatment. Eur J Public Health 2012 April;22(2):224-9.

10. Eisenberg MJ, Grandi SM, Gervais A, et al. Bupropion for smoking cessation in patients hospitalized with acute myocardial infarction: a randomized, placebo-controlled trial. J Am Coll Cardiol 2013 February 5;61(5):524-32.

11. EuroQol--A new facility for the measurement of health-related quality of life. The EuroQol Group. Health Policy 1990 December;16(3):199-208.

12. Shaw JW, Johnson JA, Coons SJ. US valuation of the EQ-5D health states: development and testing of the D1 valuation model. Med Care 2005 March;43(3):203-20.

13. Schweikert B, Hahmann H, Leidl R. Validation of the EuroQol questionnaire in cardiac rehabilitation. Heart 2006 January;92(1):62-7.

14. Ellis JJ, Eagle KA, Kline-Rogers EM, Erickson SR. Validation of the EQ-5D in patients with a history of acute coronary syndrome. Curr Med Res Opin 2005 August;21(8):1209-16.

15. Kahyaoglu SH, Unsar S. Is EQ-5D a valid quality of life instrument in patients with acute coronary syndrome? Anadolu Kardiyol Derg 2011 March;11(2):156-62.

16. Beck AT, Steer RA, Brown GK. Manual for the Beck Depression Inventory-II. San Antonio, TX: Psychological Corporation; 1996.

17. Heatherton TF, Kozlowski LT, Frecker RC, Fagerstrom KO. The Fagerstrom Test for Nicotine Dependence: a revision of the Fagerstrom Tolerance Questionnaire. $\mathrm{Br} J$ Addict 1991 September;86(9):1119-27.

18. Rieckmann N, Kronish IM, Shapiro PA, Whang W, Davidson KW. Serotonin reuptake inhibitor use, depression, and long-term outcomes after an acute coronary syndrome: a prospective cohort study. JAMA Intern Med 2013 June 24;173(12):1150-1.

19. Mulder I, Tijhuis M, Smit HA, Kromhout D. Smoking cessation and quality of life: the effect of amount of smoking and time since quitting. Prev Med 2001 December;33(6):653-60.

20. McClave AK, Dube SR, Strine TW, et al. Associations between smoking cessation and

J Popul Ther Clin Pharmacol Vol 21(3):e346-e356; October 8, 2014 
anxiety and depression among U.S. adults. Addict Behav 2009 June;34(6-7):491-7.

21. Wilson D, Parsons J, Wakefield M. The healthrelated quality-of-life of never smokers, exsmokers, and light, moderate, and heavy smokers. Prev Med 1999 September;29(3):13944.

22. Strine TW, Okoro CA, Chapman DP, et al. Health-related quality of life and health risk behaviors among smokers. Am J Prev Med 2005 February;28(2):182-7.

23. Sarna L, Bialous SA, Cooley ME, Jun HJ, Feskanich D. Impact of smoking and smoking cessation on health-related quality of life in women in the Nurses' Health Study. Qual Life Res 2008 December;17(10):1217-27.

24. Tillmann M, Silcock J. A comparison of smokers' and ex-smokers' health-related quality of life. J Public Health Med 1997 September;19(3):268-73.

25. Wiggers LC, Oort FJ, Peters RJ, Legemate DA, de Haes HC, Smets EM. Smoking cessation may not improve quality of life in atherosclerotic patients. Nicotine \& tobacco Research : Official Journal of the Society for Research on Nicotine and Tobacco 2006 August;8(4):581-9.

26. Quist-Paulsen P, Bakke PS, Gallefoss F. Does smoking cessation improve quality of life in patients with coronary heart disease? Scand Cardiovasc J 2006 February;40(1):11-6.

27. Taira DA, Seto TB, Ho KK, et al. Impact of smoking on health-related quality of life after percutaneous coronary revascularization. Circulation 2000 September 19;102(12):1369-74.

28. Rumsfeld JS, Ho PM, Magid DJ, et al. Predictors of health-related quality of life after coronary artery bypass surgery. Ann Thorac Surg 2004 May;77(5):1508-13. 